Gut, 1980, 21, 146-150

\title{
Study of ion transport across biopsies of ileostomy in vitro: search for evidence of intestinal 'adaptation' after colectomy
}

\author{
P C HAWKER, A I MORRIS, J MCKAY, AND L A TURNBERG ${ }^{1}$ \\ From the Department of Medicine, Hope Hospital (University of Manchester School of Medicine), \\ Salford, Lancashire
}

SUMmARY To explore the possibility that small intestinal 'adaptation' may occur after colectomy we examined the ability of ileal mucosal biopsies, taken from patients with ileostomies, to transport electrolytes in vitro. Ileostomy mucosal electrical potential difference was higher $(5.4 \pm 0.5 \mathrm{mV})$ than in normal mucosa $(3 \cdot 3 \pm 0 \cdot 3, \mathrm{P}<0 \cdot 001)$, resistance was higher $\left(98 \pm 12\right.$, against $\left.40 \cdot 3 \pm 2 \cdot 8 \Omega . \mathrm{cm}^{-2}\right)$, while short circuit current was lower $\left(54.8 \pm 6 \cdot 0\right.$; against $\left.89.9 \pm 6 \cdot 1 \mu \mathrm{A} . \mathrm{cm}^{-2}\right)$. Net sodium absorption, $1 \cdot 25 \pm 0 \cdot 41 \mu \mathrm{mol} . \mathrm{cm}^{-2} \cdot \mathrm{h}^{-1}(\mathrm{n}=6)$, rose on addition of glucose $\left(15 \mathrm{mM} . \mathrm{l}^{-1}\right)$ to $11 \cdot 57 \pm$ $0.8 \mu \mathrm{mol} . \mathrm{cm}^{-2} \cdot \mathrm{h}^{-1}(\mathrm{n}=4)$, and these were similar to results from normal ileum. Net chloride transport was also similar to normal. In one subject, with intermittent ileostomy diarrhoea, net sodium absorption was normal, $2 \cdot 14 \mu \mathrm{mol} . \mathrm{cm}^{-2} . \mathrm{h}^{-1}$, but there was marked active chloride secretion, $14 \cdot 03$ $\mu \mathrm{mol} . \mathrm{cm}^{-2} \cdot \mathrm{h}^{-1}$. These studies do not provide any evidence of enhanced electrolyte absorption across ileal mucosa as a response to colectomy. Some cases of ileostomy diarrhoea may be due to active chloride secretion.

After colectomy, the volume of ileostomy effluent decreases over a seven to 10 day period and becomes less fluid, suggesting that there is increased intestinal fluid absorption (Smiddy et al., 1960; LeVeen et al., 1962; Kanaghinis et al., 1963). This change is accompanied by an increased transmucosal electrical potential difference which, it has been proposed, may reflect enhanced sodium absorption (Isaacs et al., 1976). These findings suggest that, after colectomy, a small intestinal 'adaptation' may occur with the development of an enhanced capacity for electrolyte absorption. However, Prado-p-de Moraes Filho et al. (1974), using the in vivo dialysis technique of Edmonds (1971), could not confirm this.

In order to examine ileal absorptive function more closely we have performed an in vitro study of the electrical and transport characteristics of biopsies of human ilestomy mucosa using a modified flux chamber (Ussing and Zerahn, 1951) developed in our laboratory.

\footnotetext{
${ }^{1}$ Address for correspondence: Professor L A Turnberg, Department of Medicine, Hope Hospital (University of Manchester, School of Medicine), Salford, Lancs M6 8HD, UK.

Received for publication 27 July 1979
}

\section{Methods}

\section{PATIENTS}

Ten patients, two male and eight female, with an age range of 34-66 years, were studied. Panproctocolectomy had been performed for ulcerative colitis in eight cases and for Crohn's colitis in two. All patients had well established ileostomies, the time from operation ranging from 1.5-16 years. None of the patients was taking steroids or electrolyte supplements and nine were well, passing normal volumes of semi-fluid effluent. One patient complained of intermittent ileostomy diarrhoea.

The studies were performed with the informed consent of the subjects, the protocol having been approved by the Ethical Committee of Salford Area Health Authority (Teaching).

\section{TECHNIQUES}

The potential difference (PD) across ileostomy mucosa in vivo was measured as previously described (Isaacs et al., 1976). An $\mathrm{Ag} / \mathrm{AgCl}$ skin reference electrode was placed over an intradermal bleb of saline on the forearm, and an exploring $\mathrm{Ag} / \mathrm{AgCl}$ electrode and a saline in agar bridge was placed in contact with the mucosa $10 \mathrm{~cm}$ from the 
ileostomy tip. The PD between these electrodes was recorded directly onto a calibrated chart recorder and the 'offset potential' between the skin reference and exploring electrode $(<5 \mathrm{mV})$, was subtracted from the observed transintestinal PD to give the true PD.

After recording the in vivo potential difference, two mucosal biopsies, approximately $8 \mathrm{~mm}$ in diameter, were taken from the same area of the ileum, $10 \mathrm{~cm}$ from the ileostomy tip, using a Dick suction biopsy instrument. The biopsies were rapidly transported to the laboratory and clamped between two specially designed miniature half chambers exposing an area of mucosa $3 \mathrm{~mm}$ in diameter. The mucosal biopsies were bathed on each side by $2 \mathrm{ml}$ isotonic buffer solution stirred and oxygenated with $95 \% \quad \mathrm{O}_{2} / 5 \% \quad \mathrm{CO}_{2}$ mixture, via a bubble lift mechanism and maintained at $37^{\circ} \mathrm{C}$. Two biopsies were usually mounted at the same time and histological assessment of specimens revealed no evidence of the patients' original disease. The composition of the buffer was $\mathrm{Na}^{+} 146, \mathrm{~K}^{+} 4 \cdot 2$, $\mathrm{Ca}^{++} 0 \cdot 6, \mathrm{Mg}^{++} 0 \cdot 6, \mathrm{Cl}^{-} 126, \mathrm{HCO}_{3}^{-} 27 \cdot 6, \mathrm{HPO}_{4}^{--}$ $0 \cdot 1, \mathrm{H}_{2} \mathrm{PO}_{4}^{-1} \cdot 2$, mM.L ${ }^{-1}$ (pH 7.55-7.6).

The spontaneous transmucosal PD was measured via narrow tipped electrode bridges of $3 \%$ agar in $3 \mathrm{M} \mathrm{KCl}$ connected to a high impedance digital voltmeter (Solartron A240, Solartron Electronic Group Limited, Farnborough, Hants, UK) via matched calomel half cells. The PD was reduced to zero by passage of a direct current (short circuit current, $\mathbf{I}_{\mathrm{sc}}$ ) from external batteries via $\mathrm{Ag} / \mathrm{AgCl}$ electrodes connected to the bathing solution by $1 \%$ agar in $1 \mathrm{M} \mathrm{NaCl}$ bridges. The short circuit current (Isc) was adjusted manually and a correction for the drop in potential caused by the solution between the electrode tips was applied using the method of Field et al. (1971). Tissue resistance, $\mathrm{R}$, was calculated from the open circuit $P D$ and $I_{s c}$ using $R=\frac{P D}{I_{s c}} \cdot A$, where $\mathrm{A}=$ area of tissue exposed $\left(0.0707 \mathrm{~cm}^{2}\right)$.

Isotopic fluxes were measured using $0.5 \mu \mathrm{Ci}{ }^{22} \mathrm{Na}$ and $2.5 \mu \mathrm{Ci}{ }^{36} \mathrm{Cl}$ (The Radiochemical Centre, Amersham, Bucks, England) the isotopes being added to the mucosal reservoir of one and the serosal reservoir of the other of the pair of chambers. After a 35 minute period during which isotopic equilibration occurred, isotopic fluxes were measured during two 10 minute periods from 35-55 minutes from mounting by taking successive $0.2 \mathrm{ml}$ samples from both labelled and unlabelled reservoirs. Steady state was shown to be achieved by the constancy of the fluxes. The samples were replaced with warm unlabelled buffer of the same composition. The ${ }^{22} \mathrm{Na}$ and ${ }^{36} \mathrm{C} 1$ were counted and unidirectional fluxes calculated as described previously (Isaacs et al 1976). The difference between the oppositely directed fluxes of the simultaneously incubated tissues gave the net flux of each ion. The sum of the net fluxes of all ions is equal to the total current generated across the tissue calculated in $\mu \mathrm{mol} . \mathrm{cm}^{-2} . \mathrm{h}^{-1}$ (short circuit current). Thus the difference between this current and the sum of the measured net $\mathrm{Na}$ and net $\mathrm{Cl}$ fluxes provides a figure for the sum of all other unmeasured ion fluxes and is termed the residual ion flux (JRnet). This 'flux' is likely to be largely derived from bicarbonate or hydrogen ion transfer. The effect of glucose, $15 \mathrm{mM}^{-1} \mathrm{l}^{-1}$, on steady state fluxes was measured in the 20 minute flux period starting 10 minutes after addition of glucose (65-85 minute from mounting).

The results obtained from ileostomy biopsies were compared with results previously obtained in this laboratory from normal mucosal segments obtained from operative specimens and incubated in a larger version of the biopsy chambers (Corbett et al., 1977).

When tissues are clamped between half chambers some crushing of the edges of the mucosa may occur, possibly influencing results (Dobson and Kidder, 1968). This 'edge effect' may become significant in the biopsy chambers where the area of mucosa exposed to the bathing solutions is small $\left(0.0707 \mathrm{~cm}^{2}\right)$ relative to the circumference. The edge damage was minimised by clamping the biopsies gently between two recessed, rubber ' $O$ ' rings. In order to assess the extent to which 'edge effect' influenced the results an initial series of experiments were performed using rabbit ileum. The electrical values obtained from tissue incubated in the biopsy chambers (exposed mucosal area $\left(0.0707 \mathrm{~cm}^{2}\right)$ were compared with those from tissues simultaneously incubated in the large chambers (exposed mucosal area $1.77 \mathrm{~cm}^{2}$ ).

Statistical comparisons were made using Student's $t$ test for paired and unpaired values, $\mathrm{P}<0.05$ being considered significant. Graphs were drawn by the method of least squares.

\section{Results}

\section{ELECTRICAL VALUES}

Comparison of biopsy chambers and large chambers In rabbit tissues incubated in the small 'biopsy' chamber potential difference and tissue resistance were slightly lower than in simultaneously incubated tissue in the large chamber $1 \cdot 25 \pm 0 \cdot 2$ (ISD) compared with $1 \cdot 74 \pm 0 \cdot 3 \mathrm{mV}$, and $35.0 \pm 8$ compared with $47 \cdot 2 \pm 6 \Omega . \mathrm{cm}^{-2}$ respectively $(\mathrm{n}=4)$. Short circuit current was slightly higher in the small chambers $\left(42.0 \pm 4\right.$ compared with $\left.37 \cdot 5 \pm 4 \mu \mathrm{A} . \mathrm{cm}^{-2}\right)$. This $27 \%$ lower resistance and potential difference 


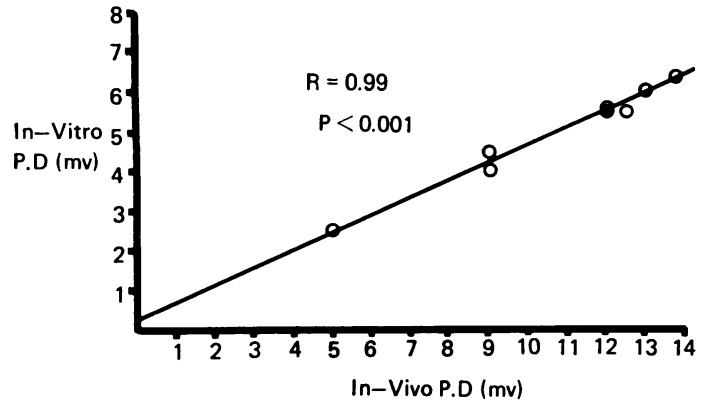

Figure In vivo electrical potential difference plotted against the in vitro potential difference of mucosal biopsies from the same subject. Where two biopsies were mounted the mean of the values is plotted. The in vitro values are those recorded during the initial stable period 10 minutes from mounting the tissue. There is a significant correlation between these values $(r=0.99$, $\mathbf{P}<0.001)$.

probably reflects a greater 'edge effect' in the small chambers.

\section{Electrical values from human ileostomy mucosa}

After mounting, there was a slow decline in short circuit current, initially $54 \cdot 8 \pm 6 \mu \mathrm{A} \cdot \mathrm{cm}^{-2}$ and reaching $40 \pm 9 \mu \mathrm{A} \cdot \mathrm{cm}^{-2}(\mathrm{n}=12)$, after 55 minutes' incubation. The initial stable values of potential difference and tissue resistance $(P D=5.4 \pm 0.5 \mathrm{mV}$, $\mathrm{R}=98 \pm 12 \Omega . \mathrm{cm} \mu^{2}, \mathrm{n}=12$ ) fell after 15 minutes' incubation and continued a slow decline to $3.95 \pm 0.6$ $\mathrm{mV}$ at 55 minutes, tissue resistance falling slightly to $80 \pm 9 \Omega . \mathrm{cm}^{-2}$. After glucose had been added to the mucosal reservoir potential difference and short circuit current rose $\left(\mathrm{PD}=5 \cdot 6 \pm 0.8 \mathrm{mV}, \mathrm{I}_{\mathrm{sc}}=101 \pm\right.$ $\left.12 \mu \mathrm{A} . \mathrm{cm}^{-2}\right)$ and tissue resistance fell $\left(70 \pm 10 \Omega \cdot \mathrm{cm}^{-2}\right.$ $\mathrm{n}=12$ ). Although the mean initial in vitro potential
Table 1 Comparison of in vitro electrical values obtained from ileostomy biopsies and from ileal mucosa obtained at operation

\begin{tabular}{llll}
\hline & $\begin{array}{l}P D \\
(m V)\end{array}$ & $\begin{array}{l}I_{\mathrm{sc}} \\
\left(u A . \mathrm{cm}^{-2}\right)\end{array}$ & $\begin{array}{l}R \\
\left(\Omega . \mathrm{cm}^{-2}\right)\end{array}$ \\
\hline $\begin{array}{l}\text { Ileostomy mucosa } \\
\mathrm{n}=12\end{array}$ & $5.4 \pm 0.5$ & $54.8 \pm 6.0$ & $98 \pm 12$ \\
$\begin{array}{l}\text { Normal ileal mucosa } \\
\mathrm{n}=48\end{array}$ & $\begin{array}{l}3.3 \pm 0.3 \\
<0.01\end{array}$ & $\begin{array}{l}89.9 \pm 6.1 \\
<0.001\end{array}$ & $\begin{array}{l}40.3 \pm 2.8 \\
<0.001\end{array}$ \\
\hline
\end{tabular}

The separate studies were unpaired and the results are the mean $( \pm 1$ SEM) of all values.

difference $(5 \cdot 4 \pm 0 \cdot 5 \mathrm{mV})$ was significantly lower than that measured in vivo $(10.8 \pm 0.9 \mathrm{mV}, \mathrm{n}=8)(\mathrm{P}<0.05)$ there was a highly significant correlation $(R=0.99$, $\mathbf{P}<0.01$ ) between values obtained from the same subject (Figure).

Comparing the initial stable electrical values from ileostomy mucosa with normal values, Table 1 shows that ileostomy mucosa developed a higher potential difference but had a lower short circuit than the normal mucosa. The most striking observation was the high tissue resistance which was more than double control values even after the slight fall in resistance occurring with prolonged incubation and despite the greater influence of 'edge effect' in the biopsy chambers.

ISOTOPIC FLUXES OF $\mathrm{Na}^{+}$AND $\mathrm{Cl}^{-}$

Isotopic sodium fluxes measured across tissue bathed in glucose free buffer showed lower unidirectional sodium fluxes across ileostomy mucosa when compared with normal, but there was no significant difference in net active sodium absorption (1.25 \pm $0.41, \mathrm{n}=6$, compared with $1.2 \pm 0.5 \mu \mathrm{mol} . \mathrm{cm}^{-2} \cdot \mathrm{h}^{-1}$, $\mathrm{n}=15$ ) (Table 2a). After glucose had been added to the mucosal reservoir net sodium absorption was

Table 2 Comparison of unidirectional fluxes of sodium and chloride across ileostomy mucosa and normal ileal mucosa obtained at operation bathed $(a)$ in glucose free buffer and $(b)$ in buffer containing $15 \mathrm{~mm}$ glucose*

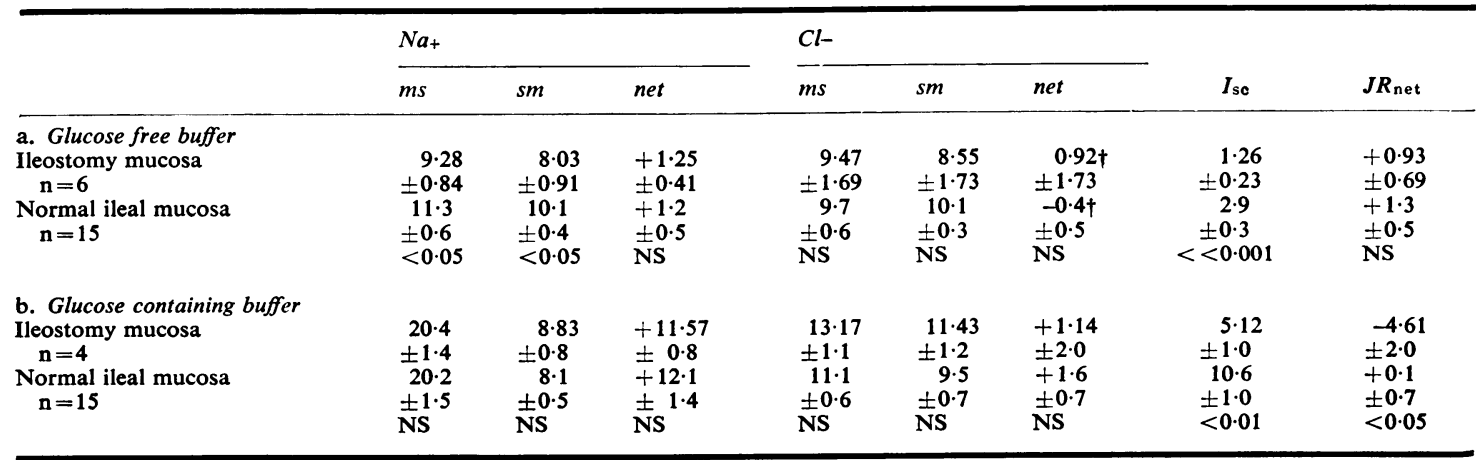

*Flux values are expressed in $\mathrm{mmol} \mathrm{cm}^{-2} \cdot \mathrm{h}^{-1}$.

†Not significantly different from zero. 
Table 3 (a) In vivo and in vitro electrical recordings obtained from a patient with ileostomy diarrhoea; (b) unidirectional fluxes across mucosal biopsies from same patient

\begin{tabular}{|c|c|c|c|c|c|c|c|c|}
\hline \multirow[b]{2}{*}{ a. } & \multirow[b]{2}{*}{$\begin{array}{l}\text { In vivo } \\
\text { In vitro }\end{array}$} & & & \multicolumn{3}{|c|}{$\begin{array}{l}\text { Electrical potential } \\
\text { difference }(P D) \\
(M V)\end{array}$} & & \multirow[t]{2}{*}{$\begin{array}{l}\text { Tissue resistance }(R) \\
\left(\Omega . \mathrm{cm}^{-2}\right)\end{array}$} \\
\hline & & & & \multicolumn{3}{|l|}{${ }_{5 \cdot 6}^{12}$} & & \\
\hline & $\mathrm{Na}+$ & & & $\mathrm{Cl}-$ & & & \multirow[b]{2}{*}{$I_{\mathrm{sc}}$} & \multirow[b]{2}{*}{ JRnet } \\
\hline & $m s$ & $s m$ & net & $m s$ & $s m$ & net & & \\
\hline b. & $8 \cdot 15$ & $6 \cdot 11$ & $+2 \cdot 14$ & $7 \cdot 47$ & 21.5 & -14.03 & $1 \cdot 11$ & $-9 \cdot 78$ \\
\hline
\end{tabular}

Flux values including $I_{\mathrm{sc}}$ are expressed in $\mathrm{mmol} \mathrm{cm} \mathrm{cm}^{-2} \cdot \mathrm{h}^{-1}$.

equally stimulated in ileostomy mucosa $(11 \cdot 57 \pm 0 \cdot 8$, $\mathrm{n}=4)$ and normal tissue $\left(12.1 \pm 1 \cdot 4 \mu \mathrm{mol} \cdot \mathrm{cm}^{-2} \cdot \mathrm{h}^{-1}\right.$, $\mathrm{n}=15$ ), and there were no significant differences in unidirectional sodium fluxes (Table $2 b$ ). There were no significant differences between chloride fluxes either in glucose free or glucose containing buffer (Table 2). When glucose was added the calculated residual ion flux became significantly different from the normal values. This response could have been due, for example, to a stimulation of bicarbonate secretion or of hydrogen absorption by glucose in the ileostomy biopsies, but the significance of this observation is unclear.

One patient had had intermittent ileostomy diarrhoea since operation, four years before the study. The in vivo and in vitro electrical measurements observed in this subject (Table 3a) were similar to those from subjects without ileostomy diarrhoea. Sodium was absorbed normally (2.14 $\mu \mathrm{mol} . \mathrm{cm}^{-2} \cdot \mathrm{h}^{-1}$ ), but there was a marked net active chloride secretion of $14.03 \mu \mathrm{mol} . \mathrm{cm}^{-2} \cdot \mathrm{h}^{-1}$, due almost entirely to an increase in the serosa to mucosa flux in this patient (Table 3). Because the chloride secretion was not electrogenic, there was a high calculated residual ion flux, possibly representing bicarbonate absorption, to maintain electroneutrality.

\section{Discussion}

It has been clearly shown here that ileostomy mucosa has a higher tissue resistance than normal ileal mucosa and it is also apparent that ileostomy mucosa is capable of maintaining a higher PD both in vivo and in vitro. In the absence of any increase in short-circuit current this higher potential difference simply reflects the increased tissue resistance. In making these changes in electrical activity and in the reduction in undirectional fluxes of sodium the ileostomy mucosa begins to superficially resemble colonic mucosa.

Although the PD in vivo was higher than that measured in vitro in ileostomy mucosa, values from the same subject did correlate well with each other and the differences probably reflect the influence of ionic concentration and $\mathrm{pH}$ gradients in vivo and the 'edge damage' effect in vitro. In any event it seems likely that the high in vivo PD is also due to increased tissue resistance rather than enhanced active sodium transport as has been proposed (Isaacs et al., 1976). It is likely that 'edge' damage in these small chambers would result in an underestimate of mucosal resistance and thus the increased resistance demonstrated here is even more striking.

The reason why mucosal resistance is altered is unclear. There were no gross histological changes on light microscopy. The possibility exists that changes in the tight junction or lateral intercellular space, occurring in response to exposure of the mucosa to an increase in ileal bacterial flora, trauma, or changes in vascularity may be responsible.

The isotopic fluxes of sodium and chloride did not show evidence of enhanced absorption of sodium or chloride, despite conditions favourable for its demonstration in the biopsies which, as they were mounted more rapidly, are likely to be more viable than the operation specimens. The diminished unidirectional fluxes probably reflected a decreased passive permeability to sodium but this affected movement in both directions equally and did not influence net sodium absorption. The significance of the increased residual ion flux in the ileostomy mucosal response to glucose is uncertain. It could represent enhanced bicarbonate secretion or hydrogen absorption stimulated by glucose but the reason for its occurrence is obscure.

In this study we have measured absorption per square $\mathrm{cm}$ of mucosal surface area, and although it is possible that our technique is insufficiently sensitive to detect small changes in absorption, we have found no evidence to support increased electrolyte absorption per unit area of ileostomy mucosa. Any enhanced absorption which might occur must therefore 
be derived from an alternative mechanism.

The study performed on the subject with ileostomy diarrhoea was of interest. The potential difference measurements in vivo and in vitro were the same as those from well ileostomists and the in vitro tissue resistance was similar to that measured in the other ileostomy biopsies. This suggests that these changes occur in all ileostomists whether they have diarrhoea or not. Although we were unable to repeat the biopsy study in this subject to confirm our results it seems likely that the chloride secretion was the major driving force in producing diarrhoea. As it was an electrically neutral process in these short circuited tissues movement of chloride must have been accompanied by transfer of another ion to maintain electro neutrality. The most likely possibilities are absorption of $\mathrm{HCO}_{3}^{-}$in exchange for chloride or secretion of $\mathrm{H}^{+}$with chloride. These cannot be distinguished in these studies and in either case diarrhoea would result from accumulation in the lumen of $\mathrm{H}^{+}$and $\mathrm{Cl}^{-}$. The fate of $\mathrm{H}^{+}$in the lumen has not been investigated in this study, but it could remain there, lowering $\mathrm{pH}$ of ileostomy discharge or it could exchange for sodium across the mucosa. The possibility that another ion such as potassium might have accompanied the chloride seems remote, and indeed the potassium concentration of this patient's ileostomy ejecta varied only between 5.4 and $8.3 \mathrm{mM}^{-1}{ }^{-1}$.

\section{References}

Corbett, C. L., Isaacs, P. E. T., Riley, A. K., and Turnberg, L. A. (1977). Human intestinal ion transport in vitro. Gut, 18, 136-140.
Dobson, J. G. Jr, and Kidder, G. W. III (1968). Edge damage effect in in vitro frog skin preparations. American Journal of Physiology, 214, 719-724.

Edmonds, C. J. (1971). Absorption of sodium and water by human rectum measured by a dialysis method. Gut, 12, 356-362.

Field, M., Fromm, D., and McColl, I. (1971). Ion transport in rabbit ileal mucosa. 1. $\mathrm{Na}$ and $\mathrm{C} 1$ fluxes and short-circuit current. American Journal of Physiology, 220, 1388-1396.

Isaacs, P. E. T., Corbett, C. L., Riley, A. K., Hawker, P. C., and Turnberg, L. A. (1976). In vitro behaviour of human intestinal mucosa. The influence of acetyl choline on ion transport. Journal of Clinical Investigation, 58, 535-542.

Isaacs, P. E. T., Horth, C. E., and Turnberg, L. A. (1976). The electrical potential difference across human ileostomy mucosa. Gastroenterology, 70, 52-58.

Kanaghinis, T., Lubran, M., and Coghill, N. F. (1963). The composition of ileostomy fluid. Gut, 4, 322-338.

LeVeen, H. H., Lyons, A., and Becker, E. (1962). Physiologic adaptation to ileostomy. American Journal of Surgery, 103, 35-41.

Prado.p.de Moraes-Filho, J., Salas-Coll, C., Blendis, L., and Edmonds, C. J. (1974). Electrical potential difference and absorption of water, sodium, and potassium by the terminal ileum of ileostomy patients. Gut, 15, 977-981.

Smiddy, F. G., Gregory, S. D., Smithe, I. B., and Goligher, J. C. (1960). Faecal loss of fluid, electrolytes, and nitrogen in colitis before and after ileostomy. Lancet, 1, 14-19.

Ussing, H. H., and Zerahn, K. (1951). Active transport of sodium as the source of electric current in the shortcircuited isolated frog skin. Acta Physiologica Scandinavica, 23, 110-127. 